http://jmscr.igmpublication.org/home/ ISSN (e)-2347-176x ISSN (p) 2455-0450 crossref DOI: https://dx.doi.org/10.18535/jmscr/v8i1.84

\author{
Dournal Of Medical Science And Clinical Research \\ IGM Publication \\ An Official Publication of IGM Publication
}

\title{
Unheeded Foreign body Left Main Bronchus, Attributing to Persistent Pneumonia in a child: A Case Report
}

\author{
Authors \\ Dr Vipan Garg ${ }^{1}$, Dr Anju Bala ${ }^{2 *}$, Dr R.S. Jaswal ${ }^{3}$ \\ ${ }^{1}$ Junior Resident, Department of Anaesthesiology, PGIMER Chandigarh \\ ${ }^{2}$ Junior Resident, Department of Paediatrics, DRPGMC Kangra at Tanda \\ ${ }^{3}$ Associate Professor, Department of Paediatrics, DRPGMC Kangra at Tanda \\ *Corresponding Author \\ Dr Anju Bala \\ Junior Resident, Department of Paediatrics, DRPGMC Kangra at Tanda, India
}

\begin{abstract}
Foreign body in respiratory tract are one of well-known causes of persistent pneumonia apart from other causes. In paediatric population most common area of lungs involved is right main bronchus which is more wide and straight and lead to impaction of foreign body mostly on right side. We are representing a case report of similar kind but on left side of lung which went unnoticed due to uncommon location further leading to persistent pneumonia which was investigated for many aetiologies but finally we retrieved a foreign body on rigid bronchoscopy under GA.

Keywords: Foreign body, Persistent Pneumonia, Left main Bronchus, Rigid Bronchoscopy.
\end{abstract}

\section{Case Report}

We report the management of a 3 years female child who presented to us with a prolonged history of intermittent high grade fever with chills, fast breathing and productive cough. A possibility of pneumonia was kept and patient was started on Ceftriaxone intravenously along with supportive treatment for 10 days and there was improvement of symptoms. So we thought that of pneumonia and treatment was a success. But improvement was temporary and she again has similar symptoms. A complete review of patient's history was done from parents who revealed that she is having these symptoms for last 4 months and the onset was sudden in nature. Previously there were no such symptoms observed by parents. On examination child had tachypnoea and respiratory distress but maintaining saturation on room air. On systemic examination there was flattening over left side of chest with decreased chest movement, dull note on percussion, marked decrease in bronchial breath sounds and increased vocal fremitus. Rest of the systemic examination was normal. Patient was investigated with X-ray chest which showed consolidation of left upper and middle zones (Image 1), which matches the previous chest radiographs provided by parents. Her routine investigations $\mathrm{CBC}$, ESR, Gastric aspirate for AFB (CBNAAT), Mantoux, BAL culture were unremarkable. Chest CT scan (Image 5) showed extensive opacities with consolidation in the left lung, with foreign body in left main bronchus. 


\section{JMSCR Vol||08||Issue||01||Page 535-537||January}

Rigid bronchoscopy was planned under general anaesthesia. $1.5 \mathrm{cms}$ long plastic foreign body (image 2,4) along with pus was localised and removed with optical forceps under vision.

Following removal of foreign body child was started on Piperacillin and Tazobactum as perpus culture sensitivity. Subsequently air entry on left side of chest improved over 1-week and child became afebrile. After completing 10 days of antibiotics course child was discharged successfully with special advice regarding chest physiotherapy. During follow up child was asymptomatic with improving nutritional status and chest radiograph (Image 3).

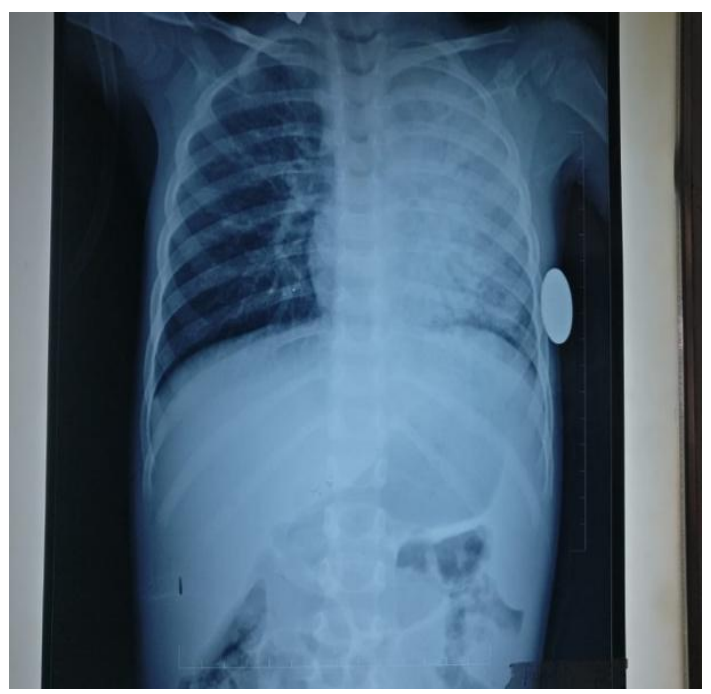

Image 1

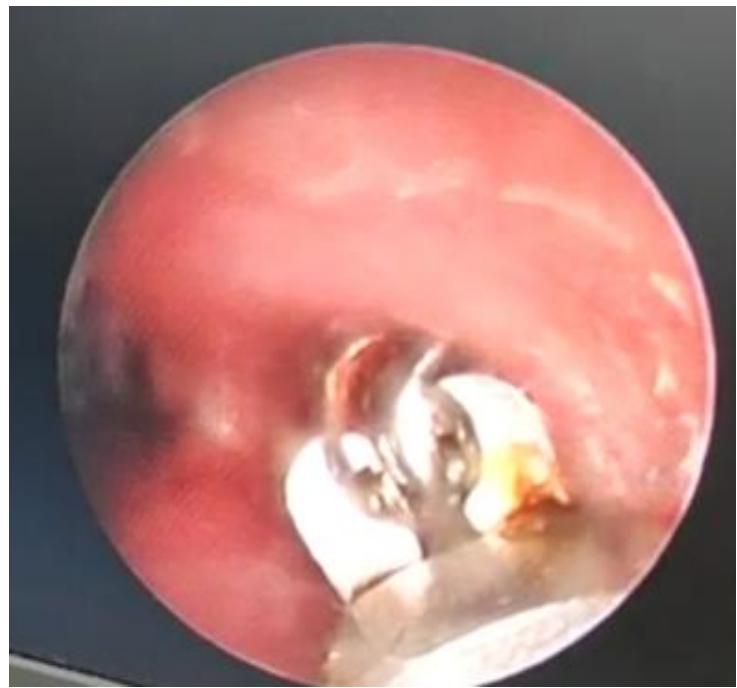

Image 2

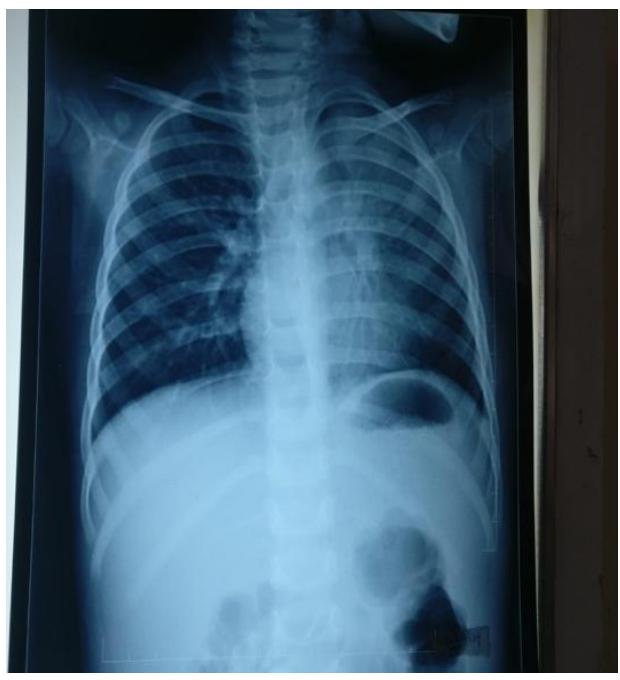

Image 3

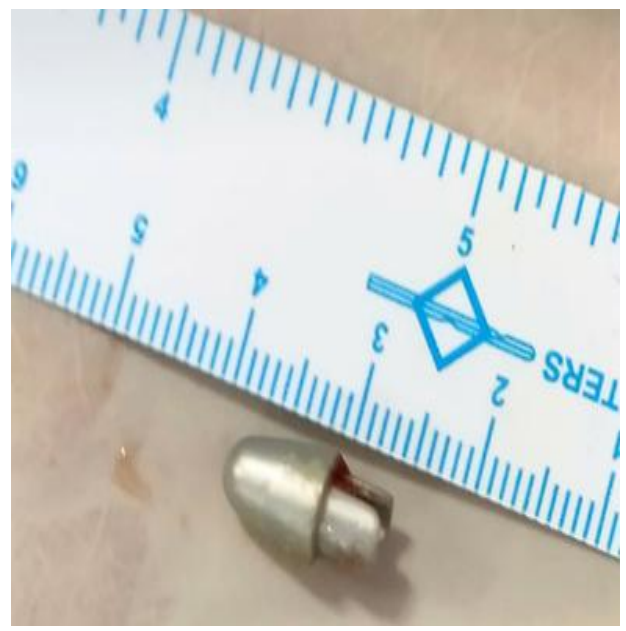

Image 4

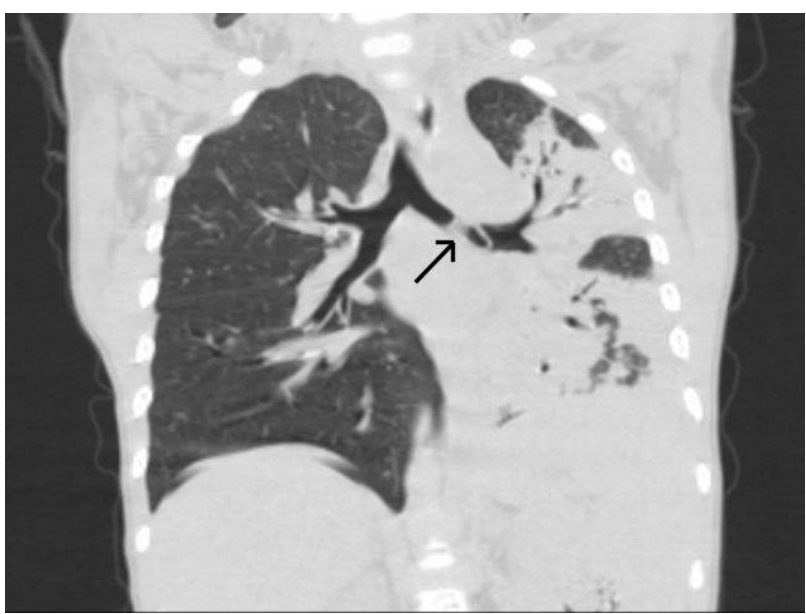

Image 5

\section{Discussion}

Foreign body in respiratory tract are one of commonest cause of persistent pneumonia in childhood period. Mostly these foreign bodies are some eating article like peanuts (most common), 
beans, pulses or some other common use objects like pen caps, erasers papers. These objects once impacted lead to persistent inflammatory changes and infections. Sometimes these foreign bodies get covered with fibrosed tissue, hence difficult to localise and remove. Foreign body in respiratory tree leads to persistent pneumonia and is most common on right side of lung. Right sided foreign bodies are common due to anatomy of right main bronchus which is more straight and wide. In our case as per traditional knowledge the differential diagnosis about foreign body was not kept in first place due to uncommon occurrence on left side. Once all the work up and investigations were unremarkable and on reviewing the history and previous chest radiographs which showed persistent findings for last 4 months and sudden onset symptoms raises the suspicion of foreign body. CT scan was planned which confirmed the diagnosis of foreign body in left main bronchus. The unusual site presentation and intermittent improvement of symptoms should not be ignored and differential of foreign body should always be kept in cases of persistent chest infection and persistent pneumonia.

\section{Conclusion}

In case of persistent pneumonia the differential of foreign body of respiratory tract must be kept irrespective of site of lung involvement. A meticulous history, clinical examination and high index of suspicion is key to diagnosis. After removal of foreign body, good antibiotic coverage as per culture sensitivity report and incentive spirometry (chest physiotherapy) are key for fast lung parenchymal recovery.

\section{Declaration of patient consent}

The authors certify that they have obtained all appropriate consent forms, in which the, patients attendant has given his consent for his child's images and other clinical information to be reported in journal. The attendant understands the name and initials will not be published and due efforts will be made to conceal identity, but anonymity cannot be guaranteed.

\section{Conflict of interest: Nil}

Source of support and sponsorship: Nil

\section{References}

1. Kumar S, Al-Abri R, Sharma A, Al-Kindi $\mathrm{H}$, Mishra P. Management of Pediatric Tracheo Bronchial Foreign Body Aspiration. Oman Med J. 2010;25(4)

2. Fidkowski CW, Zheng H, Firth PG. The anesthetic considerations of tracheobronchial foreign bodies in children: A literature review of 12,979 cases. Anesth Analg 2010;111:1016-25

3. Lauren DH. Airway foreign bodies. In: Behrman RE, Kliegman RM, Jenson HB, editors. Nelson Textbook of Pediatrics. $17^{\text {th }}$ ed. Philadelphia: Saunders; 2004. p. 1410-1.

4. Soodan A, Pawar D, Subramanium R. Anesthesia for removal of inhaled foreign bodies in children. Paediatr Anaesth 2004;14:947-52

5. Sisenda TM, Khwa-Otsyula BO, Wambani JO. Management of tracheo-bronchial foreign bodies in children. East Afr Med J 2002. Nov;79(11):580-583.

6. Black RE, Johnson DG, Matlak ME. Bronchoscopic removal of aspirated foreign bodies in children. J Pediatr Surg 1994. May;29 (5):682-684.

7. Kethmann BF, Boeckman CR. Foreign bodies in the larynx and tracheobronchial tree in children. A review of 225 cases. Ann Otol Rhinol Laryngol. 1980;89:434436. 